NBER WORKING PAPER SERIES

\title{
BALANCE SHEET INSOLVENCY AND CONTRIBUTION REVENUE IN PUBLIC CHARITIES
}

\author{
Tatiana Homonoff
}

Thomas L. Spreen

Travis St.Clair

Working Paper 26546

http://www.nber.org/papers/w26546

\author{
NATIONAL BUREAU OF ECONOMIC RESEARCH \\ 1050 Massachusetts Avenue \\ Cambridge, MA 02138 \\ December 2019
}

We gratefully acknowledge Thad Calabrese, Jacob Goldin, Ben Marx, Alex Rees-Jones, Dan Tinkelman, and Job White as well as seminar and conference participants at New York University, University of Maryland, NTA, APPAM, and ABFM for conversations and suggestions that have greatly improved the quality of this project. All remaining errors are our own. The views expressed herein are those of the authors and do not necessarily reflect the views of the National Bureau of Economic Research.

NBER working papers are circulated for discussion and comment purposes. They have not been peerreviewed or been subject to the review by the NBER Board of Directors that accompanies official NBER publications.

(C) 2019 by Tatiana Homonoff, Thomas L. Spreen, and Travis St.Clair. All rights reserved. Short sections of text, not to exceed two paragraphs, may be quoted without explicit permission provided that full credit, including $\odot$ notice, is given to the source. 
Balance Sheet Insolvency and Contribution Revenue in Public Charities

Tatiana Homonoff, Thomas L. Spreen, and Travis St.Clair

NBER Working Paper No. 26546

December 2019, Revised May 2020

JEL No. H31,L31

\section{ABSTRACT}

Using Form 990 data reported by public charities, we document significant bunching of nonprofits at near-zero net assets, the threshold for insolvency. Bunching occurs despite the fact that creditors cannot force insolvent nonprofits into involuntary bankruptcy. We show that the extent of bunching is greater among organizations that rely more heavily on contribution revenue, and that by inflating their net assets, bunching organizations are able to increase their contribution revenue relative to firms that report negative net assets. Charitable donors appear to use the net assets threshold as a heuristic for a charity's financial health; nonprofit managers, in turn, respond to the preferences of their donors.

Tatiana Homonoff

New York University

Robert F. Wagner School of Public Service 295 Lafayette Street, 2nd Floor

New York, NY 10012

and NBER

tatiana.homonoff@nyu.edu
Travis St.Clair

New York University

Robert F. Wagner

School of Public Service

295 Lafayette St, 2nd Fl

New York, NY 10012

travis.stclair@nyu.edu

Thomas L. Spreen

University of Maryland School of Public Policy

4139B Van Munching Hall

7699 Mowatt Lane

College Park, MD 20742

tlspreen@umd.edu 


\section{Introduction}

One of the key features that distinguishes for-profit and nonprofit entities in the United States is how federal law treats them in insolvency. The bankruptcy code permits creditors of for-profit corporations to file involuntary bankruptcy petitions, and consequently the typical outcome for corporations that are unable to service their debts is either liquidation or restructuring. This is not the case for nonprofit firms, whose creditors cannot initiate involuntary bankruptcy proceedings. Instead, the decision to liquidate or re-structure lies with a nonprofit organization's board of directors (Peterman and Morissette, 2004).

As such, insolvency may be less immediately consequential for nonprofit organizations. This is especially the case with balance sheet insolvency, in which an organization's liabilities exceed its assets. Balance sheet insolvency differs from cash-flow insolvency insofar as an organization may be "insolvent on the books" but still able to meet its near-term obligations. Nevertheless, nonprofit organizations that are balance sheet insolvent may face incentives to report otherwise if doing so helps to preserve their reputation with important stakeholders.

In the case of nonprofits, the most important stakeholders are typically donors. Donor contributions are the primary source of revenue for the average public charity; Internal Revenue Service Form 990 data show the median nonprofit receives 52 percent of its revenue from contributions. Consequently, how donors allocate their charitable contributions has significant implications for the strategic decisions of nonprofit firms. If donors use balance sheet solvency as a heuristic for assessing the financial health and viability of organizations (rather than the underlying value of net assets) when deciding where to allocate their charitable dollars, insolvent organizations may have an incentive to report financials that place them just above the insolvency threshold.

We investigate this question using data from the National Center for Charitable Statistics Core Financial Files, which include all 501c(3) public charities in the United States - a panel of nearly half a million public charities spanning 2005 to 2015 . Using financial information reported in the Internal Revenue Service's Form 990 or 990-EZ, we examine whether charities 
manipulate their income to avoid insolvency, and explore the consequences of this behavior. We start by documenting two features of the distribution of nonprofits. First, a considerable number of charities are balance sheet insolvent. Approximately seven percent of charities report negative net assets, or more than 22,000 charities in 2015 alone. Second, we document significant bunching at zero net assets. We examine several explanations for this result and find that the bunching is not solely a product of organization age, transfers between organizations, or a desire to spend down resources. Instead, a substantial portion of the bunching we observe appears to be due to income manipulation rather than any quirk of nonprofit financial reporting.

To quantify the magnitude of the behavioral response, we estimate the size of the excess mass just above the insolvency threshold using methods from the bunching literature (Chetty et al., 2011; Dee et al., 2019; Diamond and Persson, 2016; Kleven and Waseem, 2013). The size of the excess mass suggests that 0.2 percent of all public charities engage in income manipulation at the threshold. For context, this estimate is roughly twice the size of the observed behavioral response to the requirement that nonprofits file the Form 990 (Marx, 2018). This corresponds to an 8 percent probability that charities falling just below the threshold inflate their net assets so as to appear solvent.

Next, we explore the characteristics of bunching organizations using methods described in Diamond and Persson (2016). We find that bunching is most common among smaller organizations that receive a large proportion of their revenues from charitable contributions rather than from program fees. We find that our bunching estimates increase monotonically with the percent of revenues from contributions and that the extent of bunching is approximately five times greater for organizations in the highest quartile of contribution revenue than for firms in the lowest quartile. These findings are consistent with a model in which nonprofits are motivated to manipulate their financial reporting in order to appear balance sheet solvent so as to appeal to their donor base.

Finally, we exploit the panel structure of our data to examine the consequences of bunch- 
ing by comparing outcomes in later years for charities that manipulated their financial reporting to the outcomes of charities that were eligible to bunch but did not. Motivated by our prior findings, we first consider the effect of bunching on contribution revenue. We find no evidence of an effect of bunching on contribution revenue in the year that an organization bunches, consistent with the timing of the release of financial statements. However, we observe that bunching leads to an increase in contribution revenue in subsequent years charities near the threshold in year $t$ experience a significant 7 percent increase in contribution revenue in each of the following three years, suggesting that donors are more likely to contribute to charities just above the insolvency threshold. We also find that bunching leads to small but statistically significant increases in attrition. These exiting firms are smaller and more likely to report exactly zero net assets, evidence consistent with a model in which a subset of firms that bunch do so to deplete their assets in the year that they discontinue operations. These extensive margin effects do not substantively change our findings on the effects of bunching on contribution revenue.

Our analysis contributes to several strands of the literature on charitable giving and the private provision of public goods. First, we document new features of donor preferences and the allocation of charitable giving. Our findings are consistent with previous work showing that donors consider the financial health of the organizations to which they contribute. Prior research indicates that donors are sensitive to the amount of cash charities have on hand (Calabrese, 2011), their degree of leverage (Calabrese and Grizzle, 2012), and the amount of program revenue they earn (Okten and Weisbrod, 2000). Moreover, there is also clear evidence that nonprofits shift their behavior in response to these donor preferences (Calabrese, 2013; Krishnan and Yetman, 2011).

We also contribute to the behavioral economics literature on decision-making heuristics in charitable giving. For example, Karlan and List (2007) suggest that donors use the presence of a donation match as a heuristic for the price of giving: donors are more likely to contribute when there is a match, but are insensitive to the size of the match. Yoruk (2016) documents 
a jump in contributions for charities just above the threshold for receiving an additional star on Charity Navigator, a third-party rating agency, relative to charities just below the threshold, suggesting that donors respond to simplified benchmarks of financial health. In our context, donors may regard balance sheet solvency as a heuristic for financial health, which they use to simplify decision-making on how to best allocate scarce donative resources. Our results are also consistent with findings that individuals bunch at salient reference points - such as zero tax liability (Rees-Jones, 2017) or round-numbered marathon finishing times (Allen et al., 2016) - due to loss aversion (Kahneman and Tversky, 1979). Again, in our context, this would suggest that loss-averse donors avoid charities whose net assets fall below the donor's reference point of zero.

Finally, we build on a number of recent papers that have used bunching methods to study income manipulation among nonprofit firms. Marx (2018) shows that the average charity reduces reported income by $\$ 750-\$ 1000$ in order to avoid filing the full version of the Form 990, the information return required by the IRS of all tax-exempt organizations. St. Clair (2016) demonstrates how charities manipulate their revenues to avoid state audit requirements. While the current paper also uses bunching methods to understand the strategic responses of firms, it differs from these other papers in that the observed bunching is not driven by a regulatory requirement, but rather by preferences of key stakeholders.

This paper proceeds as follows. Section 2 provides background on insolvency and nonprofit finance. Section 3 describes the data and provides summary statistics. Section 4 presents graphical evidence of bunching at zero net assets and quantifies the size of the behavioral response. Section 5 examines the characteristics of bunching charities and provides motivation for the empirical analyses. Section 6 evaluates the effects of bunching on charitable contributions as well as other financial metrics. Section 7 concludes. 


\section{Background on Nonprofit Finance and Insolvency}

An entity is generally recognized as insolvent when it is unable to meet its outstanding obligations in full and on time. There are two versions of insolvency: cash flow insolvency and balance sheet insolvency. Cash flow insolvency occurs when an organization is unable to meet its near-term obligations due to liquidity constraints. Balance sheet insolvency occurs when a firm's total liabilities exceed its total assets; the organization is "insolvent on the books" even if it is able to service its debts in the near term. ${ }^{1}$

Under federal law, bankruptcy filings typically focus on whether or not an entity is paying its debts as they become due, i.e. whether it is cash-flow insolvent. In the private sector, the fiduciary duty of the directors of for-profit companies is to serve the interest of their company's shareholders, who own the residual (surplus) value of assets over liabilities. ${ }^{2}$ Once a for-profit corporation is unable to pay its debts, its creditors gain standing to file an involuntary bankruptcy petition under the United States Bankruptcy Code. A company may also voluntarily discharge its debts through liquidation under Chapter 7 of the United States Bankruptcy Code or reorganize under Chapter 11, and there are also separate considerations beyond liquidity that contribute to the decision to enter bankruptcy, including bankruptcy costs, tax considerations, and the ranking of interest in distributing the company's liquidated value (Bulow and Shoven, 1978; White, 1989). So long as a for-profit corporation is able to service its debts in the near-term, its creditors may not necessarily have standing to petition for involuntary bankruptcy, even if it is balance sheet insolvent (McCoid, 1987).

In the case of nonprofit organizations, creditors are ineligible to force the firm into bankruptcy, regardless of whether it is cash-flow or balance-sheet insolvent. While solvent, the fiduciary duty of nonprofit directors is to fulfill its chartered mission. Similar to for-profits, this duty expands to include the interests of the organization's creditors once

\footnotetext{
${ }^{1}$ Financial statements are typically prepared under the assumption that the reporting entity will continue to operate as a going concern. If liquidation is imminent, then generally accepted accounting principles require that financial statements be prepared under the liquidation basis of accounting (FASB, 2014).

${ }^{2}$ A company's residual value is captured in the shareholders' equity account on the balance sheet. Net assets are the nonprofit equivalent of shareholders' equity.
} 
the nonprofit approaches insolvency. Regardless, federal law does not permit a nonprofit's creditors to sue nonprofit directors, and U.S. courts have not recognized those creditors as holding a residual interest in the organization (Elliot and Hollander, 2014). While the directors of an insolvent nonprofit organization are advised to take their creditors' interests into account, their legal duty is to fulfill the organization's mission, even if that comes at their creditors' expense (Peterman and Morissette, 2004).

If insolvency does not have immediate legal ramifications for the nonprofit sector, then what incentives do organizations have to maintain positive net assets? Despite a lack of owners to lay claim to surpluses (the "nondistribution constraint") and research that finds that nonprofits are not revenue-maximizing (Okten and Weisbrod, 2000), nonprofit managers may wish to preserve the long-term viability of the organization so as to collect salaries and continue the firm's mission. This viability may be threatened if donors or other external parties attach negative consequences to a designation of insolvency.

In this paper, we focus on balance sheet insolvency because it is directly observable - and potentially salient - to anyone with access to financial information about the firm. The ability of donors and external parties to observe the financial position of nonprofit organizations has grown in recent years with the ubiquity of third-party rating agencies such as Charity Navigator and GuideStar. These sites compile and report on the financial position of nonprofit organizations based on information extracted from their annual Form 990 information returns filed with the Internal Revenue Service. Indeed, GuideStar reports specifically on whether an organization has reported negative net assets in the last five years, while Charity Navigator reports on an organization's ratio of liabilities to assets. Thus, even for unsophisticated donors with little financial knowledge, information on the insolvency threshold is available and potentially salient. 


\section{Data and Summary Statistics}

Our data source is the National Center for Charitable Statistics' (NCCS) 2005-2015 Core Financial Files for public charities, which are based on the IRS' annual Return Transaction Files. The public charities core files contain approximately 50 financial variables for all 501c(3) public charities reporting at least $\$ 50,000$ in gross receipts that filed either the Form 990 or the Form 990 EZ. ${ }^{3}$ The public charities files contain data only on 501c(3) public charities, and consequently our analysis does not include private foundations or exempt organizations that are not $501 \mathrm{c}(3) \mathrm{s}^{4}$. The data contain information on 578,282 charities for a total of just under 3.5 million annual returns.

\section{A. Graphical Evidence of Bunching and Sample Selection}

Figure 1a presents a density plot of public charities using the raw data, with the x-axis showing net assets scaled by total assets and the y-axis showing the number of organization-years. ${ }^{5}$ The figure shows substantial bunching just above the insolvency threshold. This bunching occurs despite the fact that there is no discontinuity in policy such as the requirement for organizations above a certain threshold to be audited, as in other analyses of bunching in the nonprofit sector (St. Clair, 2016; Marx, 2018).

To investigate whether the bunching we observe is due to income manipulation rather than other factors unrelated to firm responses, we impose several sample restrictions. Appendix Table 1 summarizes the restrictions and their effect on the size of the sample. These restrictions are most likely conservative and, if anything, bias our bunching estimates downwards. First, to ensure that the bunching we observe is not simply a matter of data quality,

\footnotetext{
${ }^{3}$ The Form 990 is an information return required by the IRS of all tax-exempt organizations. Organizations with gross receipts of less than $\$ 200,000$ and total assets of less than $\$ 500,000$ can file the Form 990 EZ, a simpler version of the form. Organizations with gross receipts of less than $\$ 50,000$ can file the Form 990-N (e-Postcard).

${ }^{4}$ Private foundations file a separate return, the Form 990-PF, which contains similar information as the Form 990. Because of differences in reporting and variable definitions, we do not include private foundations in our analysis. However, we report on a separate analysis of Form 990-PF data in footnote 13.

${ }^{5}$ Scaling by total assets enables us to examine organizations of disparate size. For the remainder of the paper we use 'net assets' as a shorthand for net assets as a share of total assets.
} 
whereby missing observations are coded as exact zeroes, we exclude charity-year observations with missing assets, observations with reported assets of zero or 1, and charities with consecutive years of precisely zero net assets. ${ }^{6}$ To ensure that bunching is not merely a feature of "new" charities, which are unlikely to accumulate significant net assets in their first year of operation, we exclude organizations that have been in operation for less than five years, where age is based on the year in which the IRS recognized the organization's tax exempt status. $^{7}$ Next, to allow for the possibility that some tax-exempt organizations may seek to spend down their resources each year, we exclude organizations that report an average net income of exactly zero and organizations that never report any contribution revenue. Finally, we consider whether bunching may be driven by subsidiary organizations that transfer all of their fund balance at year's end to a parent organization. We do find cases of charities who provide specialized services in the form of fund-raising or investment management for a closely related organization and who frequently transfer net assets. Consequently we remove all charities that are deemed "supporting" public charities. These restrictions leave us with a final sample of 2,182,693 observations and 331,568 distinct charities.

Figure 1b repeats the analysis in Figure 1a after cleaning the data (i.e., the first restriction in Appendix Table 1), while Figure 1c shows the final sample. We find that the extent of bunching declines due to these restrictions, as expected; however, we still observe substantial bunching just above the insolvency threshold. This suggests that the bunching we observe in our final sample is likely to be due to charities manipulating their net assets rather than any structural features of nonprofit financial reporting.

\footnotetext{
${ }^{6}$ While our final sample includes charities that report one year of precisely zero net assets, which could be consistent with income manipulation, we continue to observe substantial bunching even when we remove all exact zeros. Insofar as these exact zeros may be more likely to represent a reporting response rather than true change in the net assets of the firm, this finding suggests that at least a portion of the bunching we observe is due to a change in firm operations.

${ }^{7}$ Appendix Figure 1 shows density distributions for charities that have been in operation for different lengths of time, ranging from 2 to 24 years. While the extent of bunching declines somewhat with age, bunching persists even among organizations that have been in existence for decades.
} 


\section{B. Summary Statistics}

Table 1 reports summary statistics for the final sample. The financial variables are highly skewed, and consequently for the analyses in sections 5 and 6 we apply log transformations to the outcome variables of interest. There are two features of the data that are worth highlighting. First, a very large fraction of public charities have either no or very low liabilities. The median charity in our sample has a net assets to total assets ratio of 0.97 , implying that liabilities are only three percent of assets; the mean is 0.74 . While only about 63 percent of the organizations in the sample earn program revenue - revenue earned through the provision of goods or services to clients - those that do engage in revenue-generating activities collect more revenue on average from their programs than from contributions. The median charity in the final sample collects 52 percent of their revenues from contributions. Second, approximately six percent of the charities in our analytic sample - and seven percent in the raw data - report liabilities in excess of assets, i.e., are balance sheet insolvent. ${ }^{8}$ The relatively large proportion of insolvent firms highlights that nonprofits can continue to operate unimpeded with negative net assets.

\section{Bunching at Zero Net Assets}

\section{A. Measuring the Excess Mass}

We employ standard methods for measuring the extent of bunching and the size of the behavioral response. The bunching design was first introduced by Saez (2010) and further developed by Chetty et al. (2011) and Kleven and Waseem (2013) to identify tax-induced

\footnotetext{
${ }^{8}$ Bowman (2011) draws a distinction between for-profit and nonprofit balance sheet insolvency, arguing that nonprofits are balance sheet insolvent when their unrestricted net assets, rather than total net assets, drop below zero, since organizations with negative unrestricted net assets will be unable to discharge their obligations to their creditors. However, we focus on total net assets because it is more salient to users of financial statements and also because it is among the financial metrics highlighted by GuideStar and Charity Navigator. Moreover, while we observe bunching at zero unrestricted net assets, the majority of charities do not report temporarily or permanently restricted net assets, and consequently most of the bunching observable in unrestricted net assets represents overlap with bunching in total net assets.
} 
behavior distortions using kink points in tax schedules. Although initially developed to study the elasticity of taxable income, it has since been employed to study behavioral responses in other contexts, including among small businesses (Onji, 2009) and nonprofits (St. Clair, 2016; Marx, 2018).

The basic bunching design divides the running variable into bins and counts the number of observations within each bin. The number of excess bins on one side of the threshold is then compared to a counterfactual distribution in which no bunching occurs, with the identifying assumption being that the counterfactual distribution is smooth across the threshold. Borrowing the notation of Kleven (2016), we estimate bunching as follows:

$$
c_{j}=\sum_{i=0}^{p} \beta_{i} \cdot\left(z_{j}\right)^{i}+\sum_{i=z_{-}}^{z^{+}} \gamma_{j} \cdot 1\left[z_{j}=i\right]+v_{j}
$$

where $c_{j}$ represents the number of organizations in bin $j$ and $z$ represents the level of scaled net assets (net assets / total assets) in bin $j$. The left-hand side of the equation represents the counterfactual, estimated as a polynomial function that expresses the association between the organization count and net assets, with $p$ as the degree of the polynomial. We use a fourth order polynomial based on the Bayesian Information Criterion (BIC), which decreases monotonically for polynomials of order one through four before increasing when we add a fifth order polynomial (see Appendix Table 2). The right-hand side measures the extent of bunching by estimating the difference in the bin counts around the threshold (between $z$ - and $z+$ ) relative to the counterfactual, obtained using a series of dummy variables for bins $z$-through $z+$. Bins $z$ - to 0 represent the region of missing mass below the threshold, while bins 0 to $z+$ represent the region of excess mass.

To identify the "manipulation range" or "exclusion window" in which the empirical distribution departs from smoothness, we iteratively vary the bounds of the excluded region until we satisfy the "integration constraint;" that is, we set the area under the counterfactual distribution equal to the area under the empirical distribution, or equivalently we set the excess mass equal to the missing mass on the other side of the cutoff (Chetty et al., 2011; Diamond 
and Persson, 2016; Dee et al., 2019). This leaves us with an excluded window of -0.3 to 0.10 net assets. Figure 2 shows the density plot of public charities along with a fitted counterfactual distribution based on this excluded range. As in Figure 1, we observe significant bunching to one side of the zero net assets threshold. The density distribution is asymmetric around the threshold, with the region of missing mass extending further than the region of excess mass, as is common in empirical distributions around notches (Kleven, 2016). ${ }^{9}$ As noted previously, the bunching occurs despite the fact that there is no discontinuity in policy.

Table 2 reports our estimates of the size of the excess mass, and thus the extent of bunching. The main specification uses an exclusion window of -0.3 to 0.1 and an estimation range of -0.8 to 0.8 . Following Dee et al. (2019), we provide estimates for both total manipulation and in-range manipulation. Total manipulation is the excess mass as a percent of the total sample size, which corresponds to the percentage of total charities in the sample that bunch. In-range manipulation is the excess mass as a percent of the number of charities in the counterfactual range in the region of missing mass (bins $-z$ to 0 ), which can be interpreted as the probability of bunching conditional on falling just below the solvency threshold. We calculate standard errors using a parametric bootstrap procedure, similar to the one used in Dee et al. (2019) and Chetty et al. (2011). We draw with replacement from the distribution of residuals estimated in Equation (1) to generate a new density distribution from which we generate bootstrapped estimates of the excess mass. The standard error we report is the standard deviation of 200 of the bootstrapped estimates.

Column 1 presents our total manipulation estimate and shows that the number of excess organizations above the threshold represents approximately 0.2 percent of all public charities. This is equivalent to an 8 percent probability that charities falling just below the threshold will manipulate their financial reporting so as to appear solvent (column 4). By comparison,

\footnotetext{
${ }^{9}$ Although the distribution appears to more closely resemble those of "notches," in which agents face a discontinuous jump in their choice set, rather than "kinks," in which agents face a discontinuity in the slope of their choice set, it is possible that the threshold is a combination of a kink and a notch. While it may be advantageous for a nonprofit to remain on one side of the threshold, there also may be a bigger difference in donor perception between, e.g., -0.2 and -0.1 than there is between 0.1 and 0.2 . We thank a helpful reviewer for this insight.
} 
Marx (2018) finds that the number of excess organizations above the filing threshold for the Form 990 is equal to 0.1 percent, or approximately half the size of our estimate. ${ }^{10}$ We also provide robustness checks on our main specification to ensure that our estimates are insensitive to specification choices, such as bin size and the order of the polynomial. Columns $2,3,5$, and 6 show that these choices have very little effect on the estimated size of the excess mass; the total manipulation estimates range from 0.193 to 0.203 percent.

\section{B. Size of the Behavioral Response}

Our measurement of the excess mass enables us to estimate another behavioral parameter of interest: the extent of avoidance behavior demonstrated by charities at the threshold. By measuring how far the excess mass can be distributed into the counterfactual density distribution below the threshold, we can estimate $\delta$, the distance that the average buncher "traveled" to move above the threshold.

$$
\delta=\frac{\left(\sum_{i=0}^{z^{+}} \gamma_{j} \cdot 1\left[z_{j}=i\right]\right) \cdot \rho}{f(0)}
$$

Specifically, we multiply the number of excess organizations that we obtain from our preferred specification (column 1, table 2$)$ by $\rho$, the size of the bins (0.02 in our specification), and divide this by the height of the counterfactual density distribution at the threshold, $f(0)$. This follows the practice in other bunching studies of assuming that because the density is not very steep at the threshold, the counterfactual density distribution is approximately flat in a narrow range around the threshold. Equation (2) yields an estimate of 0.017 , suggesting that the average buncher inflates their net assets by an amount equivalent to 1.7 percent of their assets. Using the values we obtain in the next section, this response is equivalent to $\$ 1,241$ for the average (mean) buncher.

\footnotetext{
${ }^{10}$ Relatedly, we investigated whether the re-design of the Form 990 in 2008 impacted the extent of bunching we observe. We observe little difference in the size of the excess mass before and after 2008, suggesting that our results are not driven by a quirk in either version of the IRS form.
} 


\section{Who are the Bunchers?}

In this section, we turn away from estimating the extent of manipulation and focus instead on characterizing the bunchers in our sample. We seek to understand why certain types of charities might be motivated to bunch and what distinguishes the bunchers from charities that are otherwise in similar financial health. In the next section, we explore the downstream consequences of bunching.

We follow the general approach of Diamond and Persson (2016). This involves comparing the mean characteristics of the bunchers to those charities that fall just below the insolvency threshold and might have chosen to bunch but did not. We first estimate a counterfactual by fitting a set of polynomials to the region of the data outside the manipulation region, i.e., reestimating Equation (1) for the outcome of interest rather than for the density distribution. ${ }^{11}$ This allows us to calculate the average values for the bins above the threshold in the region of excess mass $\left(Y^{u p}{ }^{a l l}\right)$ as well as the average values for the bins in the empirical distribution in the region of the missing mass $\left(Y^{\text {down }}\right)$. $Y^{\text {up_all }}$ represents the average values of a combined group consisting of the "compliers" (i.e., the bunchers), and the "always-takers" (i.e., those charities that would have reported net assets just above the threshold even in the absence of income manipulation).

After calculating the average characteristics for both the empirical distribution and the counterfactual by multiplying the estimated outcome for each bin by the number of charities falling into that bin, we can distinguish the characteristics of the compliers from those of the always-takers by using the counterfactual to determine the average characteristics of the always-takers:

$$
\bar{Y}_{\text {compliers }}=\frac{N_{u p}^{t o t}}{N_{u p}^{t o t}-N_{u p}} * \bar{Y}^{u p \_a l l}-\frac{N_{u p}}{N_{u p}^{t o t}-N_{u p}} * \bar{Y}^{u p}
$$

\footnotetext{
${ }^{11}$ Because we focus on pre-determined variables in this section, we fit a single polynomial to the data outside of the manipulation region. However, in the next section, when examining outcomes that may be affected by bunching, we fit polynomials separately on both sides of the threshold and allow for a discontinuity.
} 
where $N_{u p}^{t o t}$ represents the total number of charities above the threshold in the empirical distribution, $N_{u p}$ represents the number of charities above the threshold in the counterfactual, $\bar{Y}^{\text {up_all }}$ represents the mean value of charities in the region of excess mass in the empirical distribution, and $\bar{Y}^{u p}$ represents the mean value of charities in the region of excess mass in the counterfactual. As described in the previous section, the region of excess mass extends from net assets of 0 to 0.10 . We calculate standard errors using the same parametric approach in the previous section, except that each simulation now includes a multi-step procedure: estimating the frequency counts as well as the outcomes of interest for the empirical and counterfactual distributions.

Table 3 reports our results. In the first five rows, we report the types of charities that bunch. In the bottom seven rows, we examine their financial characteristics. The nature of the charity is of course pre-determined. This is not the case with the financial metrics; as we show in the following section, bunching does affect the financial attributes of charities. To limit the potential endogeneity of the financial characteristics, we consider lagged values from the year $t-1$.

Column 1 presents the characteristics of the bunchers. Column 2 presents the mean characteristics of the charities falling just below the threshold, and column 3 presents the difference. The charities that bunch are less likely to be health or human-services charities (such as hospitals, Boys \& Girls clubs, YMCA's, and the Boy Scouts of America) and more likely to be charities in the "other" category (including environmental, international, public benefit, and religious organizations). The bunching charities also appear to be significantly smaller than the charities that do not bunch, with substantially fewer assets and lower revenue.

One characteristic of note is that bunching charities receive a higher proportion of their revenue from contribution revenue. The Form 990 breaks down revenue into three main categories: contribution revenue, program revenue, and other. Contributions include cash and non-cash amounts received as voluntary contributions from the public, government units, 
or foundations. Program revenue includes income earned by the organization in exchange for providing a good or service, such as charging admission to a museum, while "other" revenue includes investment incomes and rental income. ${ }^{12}$ That bunching charities would receive a higher proportion of their revenue from contributions is consistent with the nature of the charities in the "other" category; environmental and international organizations typically rely on donor contributions to support their activities rather than fees charged for specific services provided, as is the case with non-profit hospitals. To further probe the association between bunching and reliance on contribution revenue, Figure 3 splits the sample into four quartiles according to the percentage of revenue that charities receive from contributions and replicates the density distributions from Figure 1 separately for each quartile. While we observe graphical evidence of bunching in all four quartiles, the extent of bunching appears more pronounced among charities in the fourth quartile.

Table 4 provides the corresponding in-range manipulation estimates by contribution revenue quartile. Overall, we find that the extent of bunching grows monotonically with the reliance on contribution revenue. Among charities in the bottom two quartiles, we find a 5-6 percent probability that charities falling just below the threshold manipulate their financial reporting in order to cross the insolvency threshold. This estimate increases to 10 percent for charities in the third quartile. However, for charities in the top quartile, we observe a substantial increase in the extent of bunching - 27 percent of charities falling just below the threshold manipulate their income to appear solvent. ${ }^{13}$

\footnotetext{
${ }^{12}$ Government grants are considered contributions if they help an organization maintain services to the public, and are not considered contributions if they represent a payment for a service. Similarly, membership dues can consist of a charitable contribution portion as well as a separate portion that represents payments for benefits received (IRS, 2018).

${ }^{13}$ Our analytic sample focuses only on public charities; however, private foundations also receive contribution revenue. We conducted a separate analysis of private foundation data obtained from the NCCS over the same time period. When we apply the same sample restrictions to the foundation data, we end up with a small sample (about 73,000 observations), however we do observe bunching above the threshold, particularly among foundations that collect most of their revenue in the form of contributions. If we relax our restrictions to expand the sample, we continue to observe a positive relationship between the extent of bunching and reliance on contribution revenue. Though we are reluctant to draw firm conclusion given the small number of observations and differences in reporting between foundations and public charities, we see this as a helpful corroboration of our main findings.
} 


\section{Effect of Bunching}

In this section, we investigate the effects of bunching, that is, we examine the outcomes for public charities that manipulated their financial reporting so as to remain balance sheet solvent and compare these outcomes to charities that were eligible to bunch but did not.

\section{A. Main Results}

We start by once again using the general framework outlined by Diamond and Persson (2016). We construct an estimate of what outcomes would have looked like for charities in the exclusion window absent income manipulation. We then compare this counterfactual to the actual distribution of outcomes for charities in the same range. The difference between these two estimates represents the reduced form effect, an intent-to-treat (ITT) estimate of the effect of falling in the manipulation region. We then scale this effect by the "first stage,"

the probability of being a buncher, which we previously calculated and reported in Table 2 as the estimates of in-range manipulation. This constitutes the local average treatment effect (LATE) of bunching. The difference between these two estimates stems from separating the characteristics of the always-takers from the compliers. We estimate the counterfactual by fitting polynomials to the region of the data outside the manipulation region. We estimate the polynomials separately on both sides of the cut-off, and allow for the possibility of a discontinuous jump in the outcome at the threshold.

One challenge we face is that the financial outcomes we are interested in studying are mechanically related to net assets; by definition, bunching organizations "inflate" their net assets by somehow increasing their reported revenue, decreasing their reported expenses, or some combination. If we focus on outcomes that are themselves subject to manipulation, the estimates we calculate may not be the effects of bunching but rather the cause. However, the panel nature of the data gives us some insight into which variables are subject to manipulation as well as which variables are affected by manipulation. Specifically, we assume that it is 
not possible for bunching to have any causal effect in year $t$, the year in which manipulation occurs. Therefore, any "effect" that we observe in that year may be part of the mechanism by which charities inflate their net asset position. In contrast, if we do not observe any distortion in the outcome distribution in year $t$, but observe effects in subsequent years, this would suggest that the outcome in question was not subject to manipulation, but may instead have been affected by the decision to bunch. In effect, by examining outcomes across a variety of years, we can use our estimates from year $t$ (the year in which bunching occurs) as a benchmark against which to compare the effects of bunching in future years. ${ }^{14}$

We examine several financial variables as outcomes. First, motivated by our descriptive findings in the previous section, we examine the effects of bunching on contribution revenue. Consistent with the panel approach discussed above, if charities appear solvent by inflating their reported contribution revenue (for example, by increasing fund raising efforts to avoid insolvency), we should see an increase in contribution revenue across the threshold in year t. In contrast, if contribution revenue is not the source of income manipulation but rather donors are more likely to donate to solvent charities, we would expect to see an increase in contribution revenue in the years following the decision to bunch, but not in the year in which bunching occurs. Our assumptions regarding the timing of donor response are based on the dynamics of the release of financial information to the public. Specifically, financial statements and Form 990s are not completed and released until several months after the fiscal year-end. Moreover, websites that disseminate information regarding the financial health of charities, such as Charity Navigator or GuideStar, do not obtain or publish this information until many months after financial statements are released. It follows that if bunching has an effect on contribution revenue, it would not be observable until one or more years later.

Tables $5 \mathrm{a}$ and $5 \mathrm{~b}$ provide estimates of the impact of falling in the manipulation region (ITT) and the impact of bunching (LATE) on contribution revenue in years $t$ through $t+4$

\footnotetext{
${ }^{14}$ This would seem to suggest event study methods as an alternative empirical strategy. However, it is not feasible to precisely identify which specific public charities are bunching at any point in time.
} 
using the methodology described above. ${ }^{15}$ Column 1 shows that in the year that bunching occurs, the estimated impact of falling just above the threshold is positive, but small and not statistically significant. In contrast, we observe larger positive estimates in the two years after bunching occurs. Specifically, organizations that fall in the manipulation region in year $t$ receive $7 \log$ points more in contribution revenue in year $t+1,7.4 \log$ points in year $t+2$, and $7.3 \log$ points in year $t+3$. When the reduced form effect is scaled by the probability of bunching, the LATE indicates that bunching organizations increase their contribution revenue by 87 to $91 \log$ points in years $t+1$ through $t+3 .{ }^{16}$ The effect of bunching on contribution revenue appears to fade in year $t+4$ - the coefficient reverses sign and is no longer significant.

Figure 4 complements the regression analysis by plotting charitable contributions in year $t+1$ as a function of net assets. The figure shows a sharp increase in log contributions at the zero net assets threshold. A "donut" regression discontinuity analysis (Barreca et al., 2011) that uses the same bandwidth and excluded window as our main specification finds that there is an effect of crossing the insolvency threshold equal to 90 log points in year $t+1$, very similar to the LATE estimate we report in Table $5 \mathrm{~b}$. This suggests that the effect of bunching on contribution revenue is largely driven by the exogenous effect of crossing the solvency threshold. If instead the donut RD estimates differed substantially from our LATE estimates, it would imply that bunching firms engaged in behavior to increase their contribution revenue, such as increasing their fund-raising effort. The results we observe are consistent with the hypothesis that donors exhibit preferences for solvent firms.

Tables 6 and 7 repeat the analysis in Table 5 for expenses and program revenue respec-

\footnotetext{
${ }^{15}$ Appendix Table 3 repeats the analysis in Table 5a for each sample restriction described in Appendix Table 1. We find that our results are not sensitive to the exclusion of any individual sample restriction.

${ }^{16}$ Although these LATE estimates are quite large, the average buncher is fairly small, with median revenue and contribution levels significantly lower than the mean values reported in Table 3. For example, looking at the distribution of (non-transformed) contribution revenue, we see that charities falling just below the threshold report median contribution revenue of $\$ 74,000$ (compared to a mean value of $\$ 1.2$ million). Based on the results in Table 3, we observe that the bunchers are even smaller in terms of assets and overall revenue than charities falling below the threshold. Given that there is substantial within-charity variance in contribution revenue, our LATE estimates are large, but not implausible.
} 
tively. Again, if firms inflate their net assets by manipulating their expense reporting, we would expect to see a negative impact on expenses in the year that bunching occurs. Similarly, if firms bunch by manipulating their program revenues, we would expect to see an increase in program revenues in year $t$. If instead, bunching has an effect on expenses or program revenue, differences should emerge in the years following bunching, but not necessarily in the year that bunching occurs.

In both tables, columns 1 through 3 estimate the effect of bunching in year $t$ through $t+4$, respectively. For both expenses and program revenues, the effects of bunching are not statistically significant in the year in which manipulation occurred nor in any follow-up year. The fact that we do not obtain statistically significant results for any variable in year $t$ may appear puzzling: in order to bunch, firms must inflate revenues or decrease expenses. However, our earlier results suggest that bunchers inflate their net assets by a very small amount. Specifically, we found that the average buncher inflates their net assets by 1.7 percent of assets, or approximately $\$ 1,200$. Therefore, our analysis may not be sufficiently powered to detect changes in any one financial characteristic that allows a firm to bunch.

\section{B. Extensive Margin Responses}

One concern with our analyses in this section is that there may be extensive margin responses at the threshold, i.e., nonprofits may cease operations or fail to fill out the Form 990 as a result of becoming insolvent. In the presence of extensive margin responses, our analyses may be biased if the charities on one side of the threshold are systematically different from charities on the other side. In this section, we test for the presence of extensive margin responses and present results from alternative specifications that use an imputation strategy to account for charity exit.

To test for extensive margin responses, we first re-visit our measurement of the counterfactual density by estimating separate polynomials on both sides of the threshold, as suggested by Kopczuk and Munroe (2015) and Marx (2019). In the presence of extensive 
margin responses, the size of the missing mass would exceed the size of the excess mass, provided that the two are not constrained to be equal. Using a two-sided specification with cubic polynomials, we obtain estimates of 0.186 for the excess mass and 0.169 for the missing mass. The excess mass exceeds the missing mass, and the difference is not statistically significant (with a t-statistic of 0.26 ). Based on this test, we do not see evidence of extensive margin responses.

However, we further explore the issue by plotting attrition in year $t+1$ against the running variable (Appendix Figure 2). While we do not observe a discontinuity in exit rates at the threshold, there does appear to be an outlier caused by higher rates of exit among firms that report exactly zero net assets. One explanation for why we observe a higher exit rate for firms reporting exactly zero net assets may be that these organizations are purposefully depleting all of their assets by year end. Alternatively, there may be some firms that exit the sample out of a concern for their ability to maintain contribution revenue in the future, potentially biasing our estimates upward.

As an alternative to the two-sided test above, we examine the effect that falling in the manipulation region has on exit rates in future years using the same methods from Diamond and Persson (2016) as in the prior subsection. Specifically, we measure the effect on permanent exit from the sample in year $t+1 .{ }^{17}$ Table 8 shows that there is a small, but statistically significant positive effect on the likelihood of exiting. When we remove the exact zeroes from the sample, this effect declines but does not disappear completely. Falling in the manipulation region increases exit rates in year $t+1$ by 0.8 to 1.7 percentage points, while bunching increases the rate of exit by 11-21 percentage points.

In order to better interpret our findings, we once again estimate the characteristics of the bunching charities, except this time we estimate the characteristics using data from above as well as below the threshold. In the presence of extensive margin responses, estimating the characteristics of bunching charities using data above the threshold will reveal information

\footnotetext{
${ }^{17}$ To measure permanent exit, we exclude the last three years of our sample, so that a charity that is deemed to permanently exit is missing for at least three years before it goes unobserved.
} 
about all charities that manipulate their finances, including those who exit, while estimating the characteristics of bunching charities using data below the threshold will reveal information about only those charities that manipulate their finances and remain in the sample. The results are in Appendix Table 4. Consistent with extensive margin responses, there are some statistically significant differences between the estimates. The bunchers appear to be smaller (in assets and in revenue) when estimated using data above the threshold than when estimated using data from below, implying that the charities that manipulate their finances and then exit are smaller than the charities that manipulate their finances and remain in the sample. The charities that exit are also less likely to report program revenue and high levels of compensation.

One interpretation of these results is that, for many firms, bunching is an indication that the firm is choosing to unwind its operations. If the exit rates we observe were due to higher rates of bankruptcy and involuntary closure in the wake of bunching, then we would expect the exiting firms to be larger charities weighed down with future financial commitments. Additionally, more than half of the attrition effect we estimate is driven by firms that report exactly zero net assets; the very fact that they report exactly zero net assets may itself be a signal that they are discontinuing operations. In the absence of more information, we cannot definitively establish this interpretation, but we believe it is consistent with what we observe about the exiting charities.

Having shown that some charities in the manipulation region do exit the sample at higher rates, we next gauge the extent to which extensive margin responses may bias our estimates in Table 5. To do so, we use an imputation approach to account for the missing outcomes of firms that exit the sample. ${ }^{18}$ Specifically, we calculate the percentage change in contributions that each firm experienced during its last year in the sample. For example, if a firm experienced a 5 percent drop in contributions between year $t-1$ and year t before exiting in

\footnotetext{
${ }^{18}$ In addition to permanent exits, charities may temporarily exit the sample as a result of falling below the reporting threshold. We impute missing outcomes for charities that exit both permanently and temporarily, however we see no effect of falling in the manipulation region on temporary exit.
} 
year $t+1$, then we assume the firm would experience a continued 5 percent drop in all subsequent years. ${ }^{19}$ We regard these assumptions as conservative, particularly in the later years. The results are presented in Appendix Table 5. Our estimates do decrease in magnitude, with the largest decreases in year $t+2$. Nonetheless, our estimates of the treatment effects in years $t+1$ and $t+3$ shrink by less than 20 percent of the original magnitude and remain statistically significant. Thus, while we find some evidence of selective attrition from the sample, we do not believe the potential bias arising from extensive margin responses alters our substantive conclusions.

\section{Discussion}

In this paper, we document significant bunching of public charities at the zero net assets threshold. This bunching persists even after limiting our sample to firms that are unlikely to have a mechanical reason to report zero net assets, suggesting that firms may manipulate their income to appear balance sheet solvent. This is somewhat surprising given the lack of direct financial penalties for reporting negative net assets.

We estimate the characteristics of the bunchers and show that the firms that inflate their financial position tend to be smaller charities that earn most of their revenues from donations. We find that bunching charities report higher contributions from donors in the years after bunching than they otherwise would, suggesting that one motivation for bunching is to appeal to donor preferences.

These findings are consistent with prior research indicating that donors care about the financial health and viability of the charities they donate to. Specifically, it relates to a literature in which donors rely on heuristics to simplify their decision-making about where to spend their contribution dollars (Karlan and List, 2007; Yoruk, 2016). Our results suggest that donors may not wish to give to insolvent organizations, even though there may be very

\footnotetext{
${ }^{19}$ If a firm exits the sample but does not report an observation for $t$-1, then we extrapolate the growth rate using the most recent lagged value, e.g., $t$-2.
} 
little difference between a charity that is just barely solvent and one that is just barely insolvent, potentially due to loss-averse preferences. The emphasis of the insolvency threshold as a binary metric of financial health may be fostered in part by third-party rating agencies, such as GuideStar, which track performance metrics, including specifically whether charities have reported negative net assets. In the face of these donor preferences, nonprofit managers respond by inflating their reported financial health.

What, if any, conclusions can we draw about welfare? If the use of heuristics and thirdparty ratings lead to the misallocation of charitable dollars, for example, as a result of lossaverse donors over-emphasizing solvency relative to more meaningful indicators of a firm's financial health, then the use of simplified financial metrics in the nonprofit sector may have negative welfare consequences. Alternatively, if the use of these heuristics improves the allocation of charitable donations, they may enhance the efficiency of public goods provision. Additionally, if the increase in charitable contributions that we document reflects an increase in overall donations for the sector as a whole, it is possible bunching could actually increase public goods provision. In the absence of clear performance metrics, it is difficult to definitively conclude that bunching firms operate less efficiently. Moreover, we have confined our analysis to a specific region of the data and our findings may have limited generalizability to firms in better financial condition. We leave to future work to expand on the implications of donor preferences and the use of heuristics for the allocative efficiency of charitable contributions. 


\section{References}

Allen, Eric J, Patricia M Dechow, Devin G Pope, and George Wu. 2016. "Reference-dependent preferences: Evidence from marathon runners." Management Science, 63(6): 1657-1672.

Barreca, Alan I, Melanie Guldi, Jason M Lindo, and Glen R Waddell. 2011. "Saving babies? Revisiting the effect of very low birth weight classification." The Quarterly Journal of Economics, 126(4): 2117-2123.

Bowman, Woods. 2011. Finance Fundamentals for Nonprofits. Vol. 2, John Wiley \& Sons.

Bulow, Jeremy I, and John B Shoven. 1978. "The Bankruptcy Decision." The Bell Journal of Economics, 437-456.

Calabrese, Thad. 2013. "Running on Empty: The Operating Reserves of US Nonprofit Organizations." Nonprofit Management and Leadership, 23(3): 281-302.

Calabrese, Thad, and Cleopatra Grizzle. 2012. "Debt, Donors, and the Decision to Give." Journal of Public Budgeting, Accounting 8 Financial Management, 24(2): 221254.

Calabrese, Thad D. 2011. "Do Donors Penalize Nonprofit Organizations with Accumulated Wealth?" Public Administration Review, 71(6): 859-869.

Chetty, Raj, John N Friedman, Tore Olsen, and Luigi Pistaferri. 2011. "Adjustment Costs, Firm Responses, and Micro vs. Macro Labor Supply Elasticities: Evidence from Danish Tax Records." The Quarterly Journal of Economics, 126(2): 749-804.

Dee, Thomas S, Will Dobbie, Brian A Jacob, and Jonah Rockoff. 2019. "The causes and consequences of test score manipulation: Evidence from the new york regents examinations." American Economic Journal: Applied Economics, 11(3): 382-423. 
Diamond, Rebecca, and Petra Persson. 2016. "The Long-term Consequences of Teacher Discretion in Grading of High-stakes Tests." National Bureau of Economic Research 22207.

Elliot, Dana, and Evan Hollander. 2014. "Navigating a Nonprofit Corporation Through Bankruptcy." Nonprofit Quarterly, April 29, 2014.

FASB. 2014. "Presentation of Financial Statements - Going Concern: Disclosure of Uncertainties about an Entity's Ability to Continue as a Going Concern."

IRS. 2018. "2018 Instructons for Form 990 Return or Organization Exempt from Income Tax."

Kahneman, Daniel, and Amos Tversky. 1979. "Prospect Theory: An Analysis of Decision under Risk." Econometrica, 47(2): 263-292.

Karlan, Dean, and John A List. 2007. "Does Price Matter in Charitable Giving? Evidence from a Large-scale Natural Field Experiment." American Economic Review, 97(5): 1774-1793.

Kleven, Henrik Jacobsen. 2016. "Bunching." Annual Review of Economics, 8: 435-464.

Kleven, Henrik J, and Mazhar Waseem. 2013. "Using Notches to Uncover Optimization Frictions and Structural Elasticities: Theory and Evidence from Pakistan." The Quarterly Journal of Economics, 128(2): 669-723.

Kopczuk, Wojciech, and David Munroe. 2015. "Mansion tax: The effect of transfer taxes on the residential real estate market." American economic Journal: economic policy, $7(2): 214-57$.

Krishnan, Ranjani, and Michelle H Yetman. 2011. "Institutional Drivers of Reporting Decisions in Nonprofit Hospitals." Journal of Accounting Research, 49(4): 1001-1039.

Marx, Benjamin M. 2018. "The Cost of Requiring Charities to Report Financial Information." Working Paper. 
Marx, Benjamin M. 2019. "Dynamic Bunching Estimation with Panel Data." 2019 MPRA Paper \#88647.

McCoid, John C. 1987. "The Occasion for Involuntary Bankruptcy." American Bankrruptcy Law Journal, 61: 195.

Okten, Cagla, and Burton A Weisbrod. 2000. "Determinants of Donations in Private Nonprofit Markets." Journal of Public Economics, 75(2): 255-272.

Onji, Kazuki. 2009. "The Response of Firms to Eligibility Thresholds: Evidence from the Japanese Value-added Tax." Journal of Public Economics, 93(5): 766 - 775.

Peterman, Nancy A, and Sherri Morissette. 2004. "Directors' Duties in the Zone of Insolvency: The Quandary of the Nonprofit Corporation." American Bankruptcy Institute Law Review, 23: 12 .

Rees-Jones, Alex. 2017. "Quantifying loss-averse tax manipulation." The Review of Economic Studies, 85(2): 1251-1278.

Saez, Emmanuel. 2010. "Do Taxpayers Bunch at Kink Points?" American Economic Journal: Economic Policy, 2(3): 180-212.

St. Clair, Travis. 2016. "How Do Nonprofits Respond to Regulatory Thresholds: Evidence From New York's Audit Requirements." Journal of Policy Analysis and Management, 35(4): $772-790$.

White, Michelle J. 1989. "The Corporate Bankruptcy Decision." Journal of Economic Perspectives, 3(2): 129-151.

Yoruk, Baris K. 2016. "Charity Ratings." Journal of Economics \& Management Strategy, 25(1): 195-219. 
Figure 1a: Bunching in Raw Data

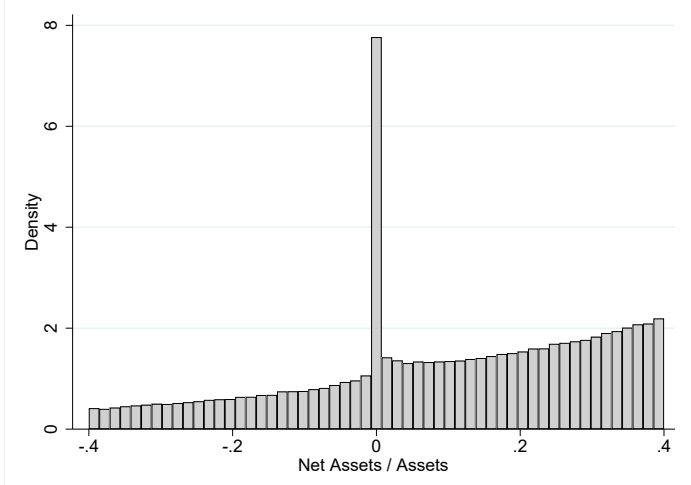

Figure 1b: Bunching After Data Cleaning

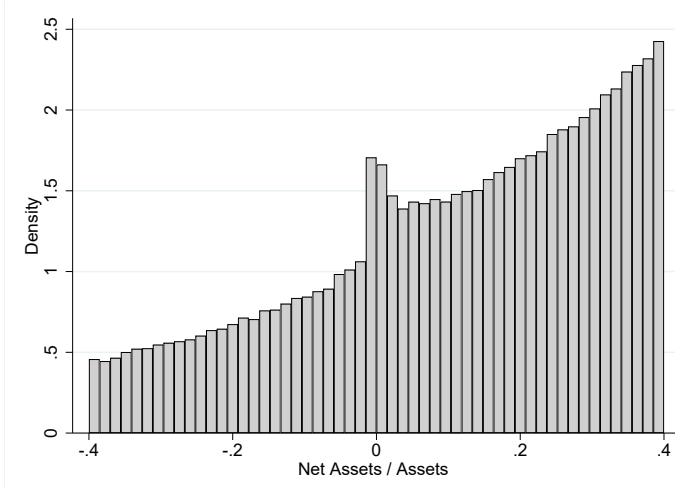

Figure 1c: Bunching in Final Sample

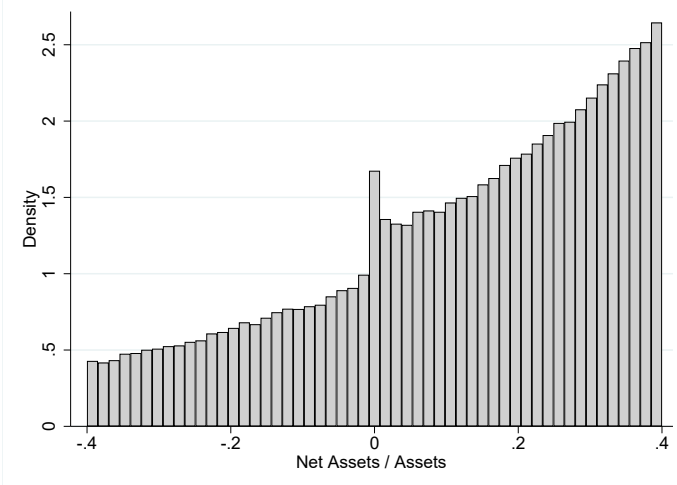

Note: Figure $1 \mathrm{~b}$ shows the density distribution of public charities after cleaning the data but before placing any restrictions on the sample. Figure 1c shows the distribution for our analytic sample after imposing a series of sample restrictions. 


\section{Figure 2: Bunching at Near-Zero Net Assets}

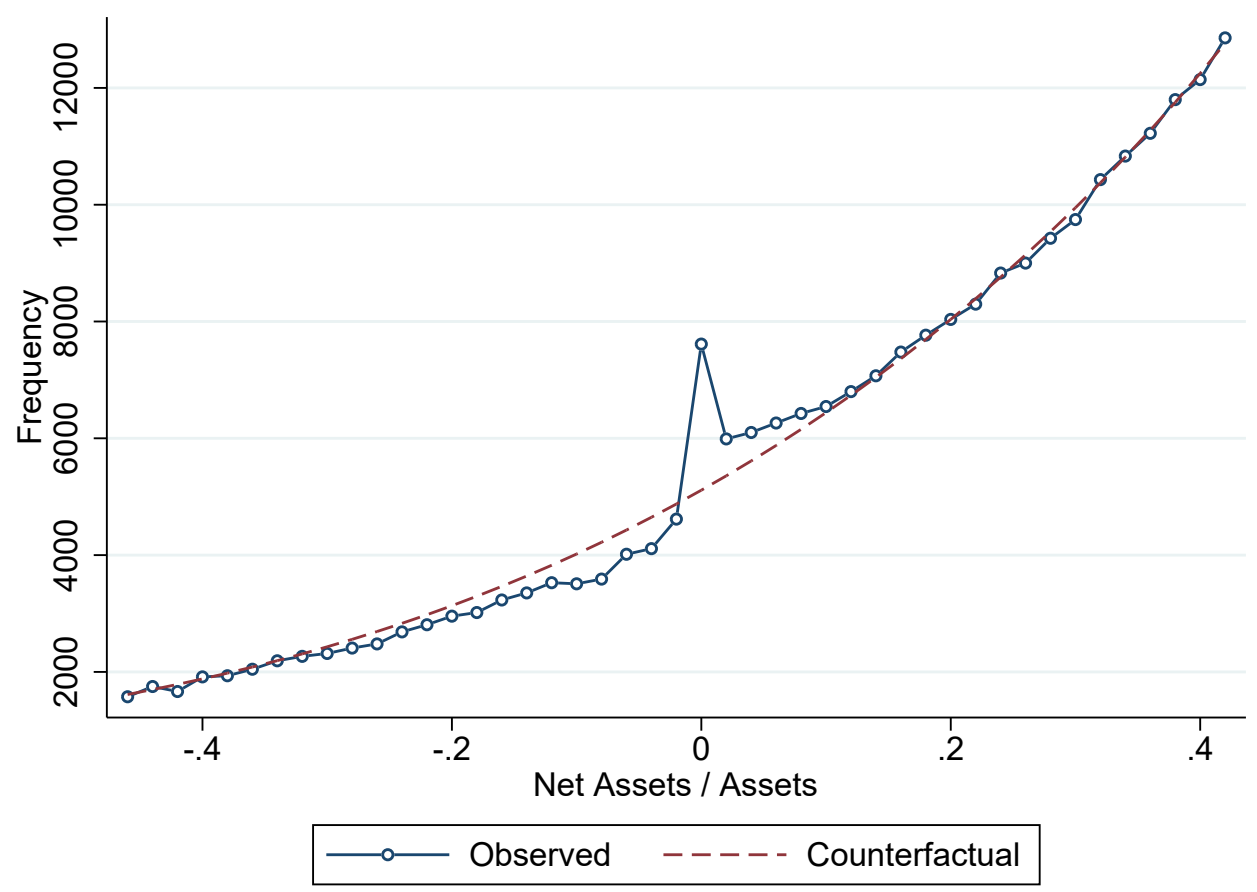

Note: This figure shows the density distribution of public charities in the vicinity of zero net assets. The dashed line beneath the observed distribution is a fourth degree polynomial fitted to observations outside the manipulated region $(-0.3-0.10)$. Each point represents the number of charity-years in a bin of size 0.02 . 
Figure 3: Bunching by the Percentage of Revenues from Contributions (Quartiles)

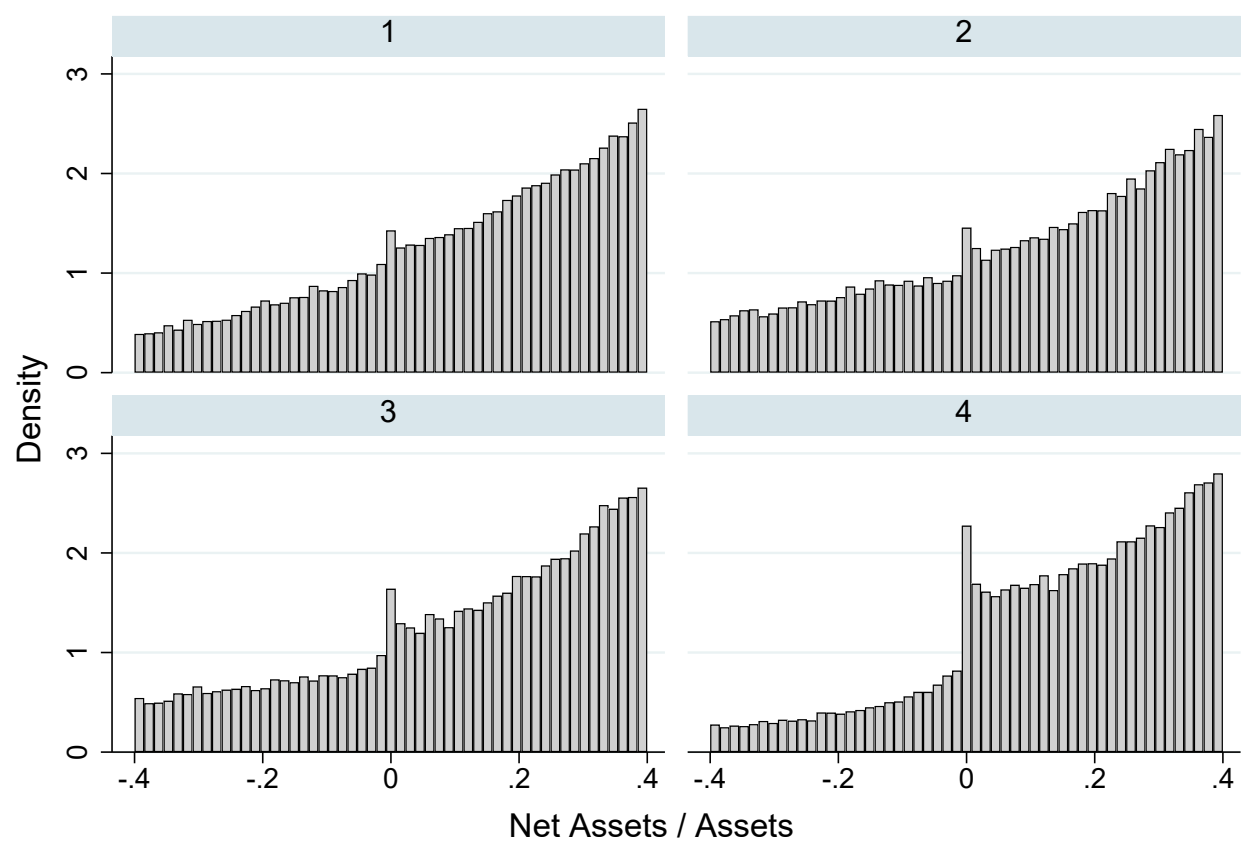

Note: This figure shows heterogeneity in the extent of bunching by splitting the sample into quartiles according to the percentage of revenues that charities receive from contributions. 
Figure 4: Log Contributions, Year $t+1$

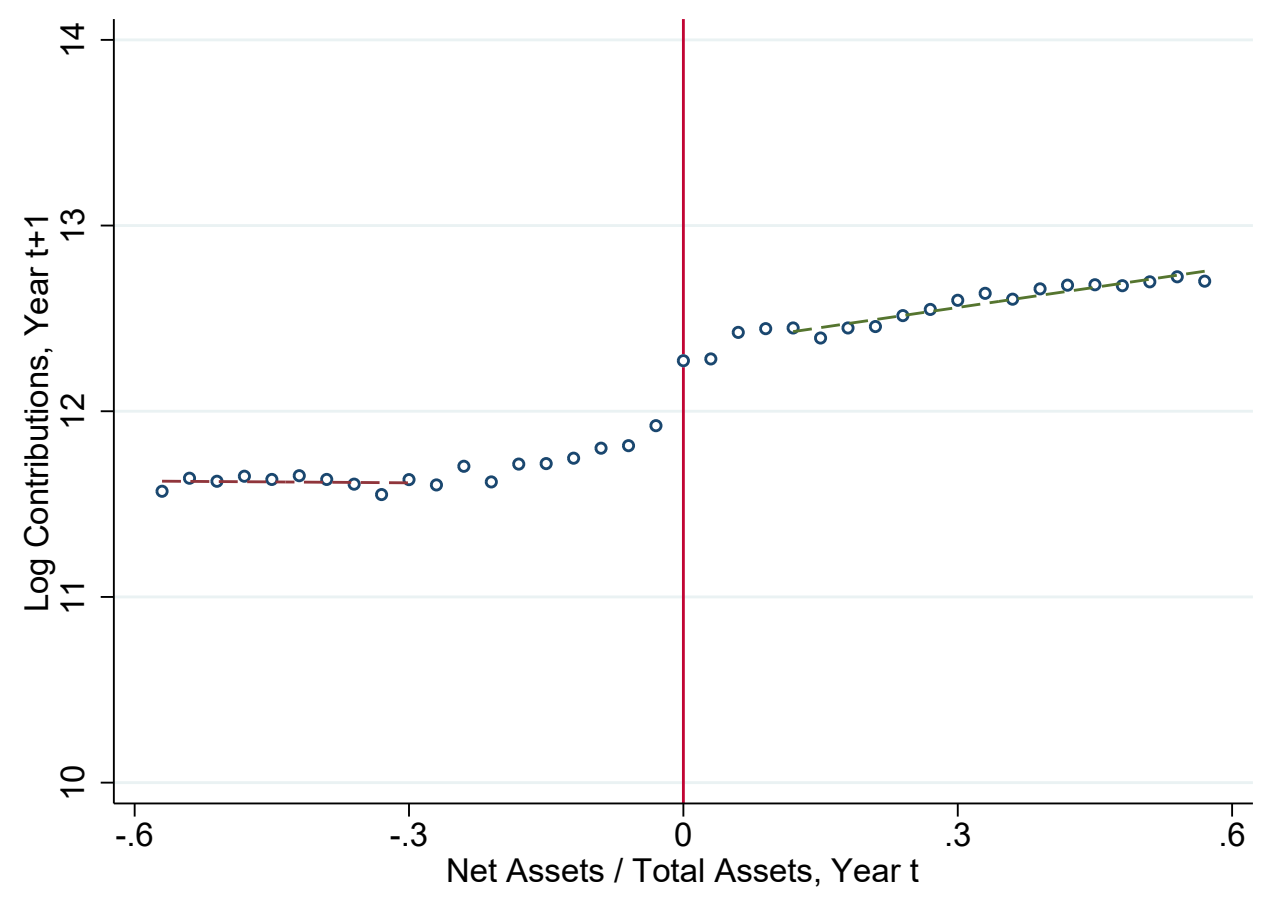

Note: The figure plots log contributions in year $t+1$ by net assets in year $t$ where year $t$ is defined as the year in which bunching occurs. Each observation represents the local sample mean for bins of size 0.03. The dashed-lines are linear trends fit to the observations that fall outside of the manipulation range. 
Table 1: Summary Statistics

\begin{tabular}{lccc}
\hline & \multicolumn{3}{c}{ Analytic Sample } \\
& Mean & Median & SD \\
& $(1)$ & $(2)$ & $(3)$ \\
\hline Assets (millions) & 11 & 0.25 & 233 \\
Liabilities (millions) & 4.4 & 0.008 & 96 \\
Net Assets / Assets & 0.74 & 0.97 & 0.55 \\
Contributions (millions) & 1.3 & 0.074 & 18 \\
Program Revenue (millions) & 4.8 & 0.022 & 108 \\
Contributions / Revenue & 0.51 & 0.52 & 0.39 \\
Expenses (millions) & 6.1 & 0.20 & 112 \\
Age of Organization & 24 & 19 & 16 \\
Insolvent (Net Assets $<0)$ & 0.06 & 0 & 0.24 \\
\hline
\end{tabular}

Note: Data come from the National Center of Charitable Statistics' (NCCS) 2005-2015 core files for public charities. $\mathrm{N}=2,182,693$ observations, 331,568 charities. The ratio variables have been windsorized at the top and bottom 1 percent of the distribution. 
Table 2: Measures of Bunching

\begin{tabular}{lcccccc}
\hline & \multicolumn{3}{c}{ Total } & \multicolumn{3}{c}{ In-Range } \\
& $(1)$ & $(2)$ & $(3)$ & $(4)$ & $(5)$ & $(6)$ \\
\hline \multirow{2}{*}{ Excess Mass } & $0.196^{* *}$ & $0.193^{* *}$ & $0.203^{* *}$ & $8.06^{* *}$ & $7.93^{* *}$ & $8.44^{* *}$ \\
& $(0.020)$ & $(0.014)$ & $(0.019)$ & $(0.835)$ & $(0.587)$ & $(0.817)$ \\
Bin Size & 0.02 & 0.01 & 0.02 & 0.02 & 0.01 & 0.02 \\
Polynomial & Fourth & Fourth & Fifth & Fourth & Fourth & Fifth \\
\hline
\end{tabular}

Note: ${ }^{* *} \mathrm{p}<0.01$ and ${ }^{*} \mathrm{p}<0.05$. This table presents estimates of the manipulation in the sample under alternative measurement assumptions. Manipulation is measured by the excess mass to the right of the solvency threshold. Total manipulation is the excess mass as a percentage of all charities in the sample. In-range manipulation is the excess mass relative to the counterfactual distribution in the range of the missing mass, or the probability of manipulation conditional on reporting net assets just below the cut-off. Standard errors are calculated using the parametric bootstrap procedure described in the text. The exclusion window ranges from -0.3 to +0.1 net assets / assets. $\mathrm{N}=2,182,693$ (total sample), $\mathrm{N}=$ 625,241 within the range of estimation $(-0.8$ to +0.8 net assets / assets $)$. 


\section{Table 3: Characteristics of Bunchers}

\begin{tabular}{|c|c|c|c|}
\hline & $\begin{array}{c}\text { Bunching } \\
\text { Charities } \\
\text { (1) }\end{array}$ & $\begin{array}{c}\text { Falls in Region } \\
\text { of Missing Mass } \\
(2)\end{array}$ & $\begin{array}{c}\text { Difference } \\
\text { (3) }\end{array}$ \\
\hline \multicolumn{4}{|l|}{ Type of Charity } \\
\hline Arts, Culture, \& Humanities & 0.094 & 0.072 & $\begin{array}{c}0.022^{* *} \\
(0.009)\end{array}$ \\
\hline Education & 0.183 & 0.113 & $\begin{array}{c}0.070^{* *} \\
(0.023)\end{array}$ \\
\hline Health and Human Services & 0.316 & 0.670 & $\begin{array}{c}-0.353^{* *} \\
(0.047)\end{array}$ \\
\hline Other & 0.407 & 0.146 & $\begin{array}{c}0.262^{* *} \\
(0.026)\end{array}$ \\
\hline \multicolumn{4}{|l|}{ Financial Characteristics } \\
\hline Log Assets, $t-1$ & 12.2 & 13.7 & $\begin{array}{c}-1.55^{* *} \\
(0.153)\end{array}$ \\
\hline Log Revenue, $t-1$ & 13.3 & 13.8 & $\begin{array}{l}-0.449 \\
(0.275)\end{array}$ \\
\hline Percent Revenue from Contributions, $t-1$ & 0.746 & 0.398 & $\begin{array}{c}0.348^{* *} \\
(0.024)\end{array}$ \\
\hline Reported Program Revenue (Yes/No), $t-1$ & 0.259 & 0.827 & $\begin{array}{c}-0.568^{* *} \\
(0.041)\end{array}$ \\
\hline Total Compensation as Percent of Expenses, $t-1$ & 0.253 & 0.314 & $\begin{array}{l}-0.061 \\
(0.034)\end{array}$ \\
\hline
\end{tabular}

Note: ${ }^{* *} \mathrm{p}<0.01$ and ${ }^{*} \mathrm{p}<0.05$. This table presents characteristics of the bunching charities and compares these characteristics to all charities that fall just below the threshold and thus also might have chosen to bunch. The characteristics of the bunching charities are distinguished from the charities that otherwise fall above the threshold (the "always-takers") by using an estimated counterfactual to determine the characteristics of the always-takers. To obtain the counterfactual estimates, we fit polynomials to the observed distribution outside of the manipulation region. Column 3 presents the difference between the estimates. Charities in the "other" category include environmental, international, public benefit, and religious organizations. Standard errors are calculated using the parametric bootstrap procedure described in the text. 
Table 4: Bunching by the Percent Revenues from Contributions (Quartiles)

\begin{tabular}{lcccc}
\hline & First Quartile & $\begin{array}{c}\text { Second Quartile } \\
(1)\end{array}$ & $\begin{array}{c}\text { Third Quartile } \\
(2)\end{array}$ & $\begin{array}{c}\text { Fourth Quartile } \\
(3)\end{array}$ \\
\hline Excess Mass & $5.40^{* *}$ & $5.54^{* *}$ & $9.54^{* *}$ & $(4)$ \\
& $(0.976)$ & $(1.10)$ & $(1.84)$ & $(3.49)$ \\
& & & & $529.5^{* *}$ \\
$\mathrm{~N}$ & 529,013 & 529,010 & 529,007 & 529,003 \\
\hline
\end{tabular}

Note: ${ }^{* *} \mathrm{p}<0.01$ and ${ }^{*} \mathrm{p}<0.05$. This table presents measurements of the excess mass by quartiles of the percentage of revenue that charities receive from contributions. All estimates reflect in-range manipulation, i.e., the probability of manipulation conditional on reporting net assets just below the cut-off. Standard errors are calculated using the parametric bootstrap procedure described in the text. We remove observations with percentages less than zero or greater than one. 


\section{Table 5a: Reduced Form: Impact of Falling in Manipulation Region on Contribution Revenue}

\begin{tabular}{cccccc}
\hline & \multicolumn{5}{c}{ Log Contributions } \\
& Year $t$ & Year $t+1$ & Year $t+2$ & Year $t+3$ & Year $t+4$ \\
& $(1)$ & $(2)$ & $(3)$ & $(4)$ & $(5)$ \\
\hline \multirow{3}{*}{ Intent-to-Treat } & 0.025 & $0.070^{*}$ & $0.074^{*}$ & $0.073^{*}$ & -0.037 \\
& $(0.025)$ & $(0.027)$ & $(0.031)$ & $(0.035)$ & $(0.037)$ \\
\hline
\end{tabular}

Table 5b: Impact of Bunching on Contribution Revenue (LATE)

\begin{tabular}{cccccc}
\hline \multicolumn{6}{c}{ Log Contributions } \\
& $\begin{array}{c}\text { Year } t \\
(1)\end{array}$ & $\begin{array}{c}\text { Year } t+1 \\
(2)\end{array}$ & $\begin{array}{c}\text { Year } t+2 \\
(3)\end{array}$ & $\begin{array}{c}\text { Year } t+3 \\
(4)\end{array}$ & $\begin{array}{c}\text { Year } t+4 \\
(5)\end{array}$ \\
\hline \multirow{3}{*}{ LATE } & 0.306 & $0.868^{*}$ & $0.913^{*}$ & $0.904^{*}$ & -0.460 \\
& $(0.315)$ & $(0.353)$ & $(0.398)$ & $(0.446)$ & $(0.480)$ \\
\hline
\end{tabular}

Note: ${ }^{* *} \mathrm{p}<0.01$ and ${ }^{*} \mathrm{p}<0.05$. Table 5 a presents estimates of the impact of falling in the manipulation region on log contributions, while Table $5 \mathrm{~b}$ presents estimates of the effect of bunching on log contributions. The counterfactual is estimated from linear regressions of $\log$ contributions on net assets, estimated separately on both sides of the cut-off. The counterfactual uses only data from outside the manipulation region. Standard errors are calculated using the parametric bootstrap procedure described in the text. 


\section{Table 6a: Reduced Form: Impact of Falling in Manipulation Region on Expenses}

\begin{tabular}{cccccc}
\hline & \multicolumn{6}{c}{ Log Expenses } \\
& $\begin{array}{c}\text { Year } t \\
(1)\end{array}$ & $\begin{array}{c}\text { Year } t+1 \\
(2)\end{array}$ & $\begin{array}{c}\text { Year } t+2 \\
(3)\end{array}$ & $\begin{array}{c}\text { Year } t+3 \\
(4)\end{array}$ & $\begin{array}{c}\text { Year } t+4 \\
(5)\end{array}$ \\
\hline \multirow{3}{*}{ Intent-to-Treat } & 0.004 & 0.025 & 0.055 & 0.067 & 0.073 \\
& $(0.042)$ & $(0.044)$ & $(0.044)$ & $(0.046)$ & $(0.047)$ \\
\hline
\end{tabular}

Table 6b: Impact of Bunching on Expenses (LATE)

\begin{tabular}{cccccc}
\hline \multicolumn{6}{c}{ Log Expenses } \\
& $\begin{array}{c}\text { Year } t \\
(1)\end{array}$ & $\begin{array}{c}\text { Year } t+1 \\
(2)\end{array}$ & $\begin{array}{c}\text { Year } t+2 \\
(3)\end{array}$ & $\begin{array}{c}\text { Year } t+3 \\
(4)\end{array}$ & $\begin{array}{c}\text { Year } t+4 \\
(5)\end{array}$ \\
\hline \multirow{2}{*}{ LATE } & 0.048 & 0.304 & 0.682 & 0.830 & 0.907 \\
& $(0.532)$ & $(0.557)$ & $(0.557)$ & $(0.585)$ & $(0.602)$ \\
\hline
\end{tabular}

Note: ${ }^{* *} \mathrm{p}<0.01$ and ${ }^{*} \mathrm{p}<0.05$. Table 6 a presents estimates of the impact of falling in the manipulation region on log expenses, while Table $6 \mathrm{~b}$ presents estimates of the effect of bunching on log expenses. The counterfactual is estimated from linear regressions of log expenses on net assets, estimated separately on both sides of the cut-off. The counterfactual uses only data from outside the manipulation region. Standard errors are calculated using the parametric bootstrap procedure described in the text. 


\section{Table 7a: Reduced Form: Impact of Falling in Manipulation Region on Program Revenue}

\begin{tabular}{cccccc}
\hline & \multicolumn{5}{c}{ Log Program Revenue } \\
& Year $t$ & Year $t+1$ & Year $t+2$ & Year $t+3$ & Year $t+4$ \\
$(1)$ & $(2)$ & $(3)$ & $(4)$ & $(5)$ \\
\hline \multirow{3}{*}{ Intent-to-Treat } & 0.014 & 0.025 & 0.038 & 0.064 & 0.069 \\
& $(0.059)$ & $(0.059)$ & $(0.059)$ & $(0.060)$ & $(0.065)$ \\
\hline
\end{tabular}

Table 7b: Impact of Bunching on Program Revenue (LATE)

\begin{tabular}{cccccc}
\hline \multicolumn{6}{c}{ Log Program Revenue } \\
& $\begin{array}{c}\text { Year } t \\
(1)\end{array}$ & $\begin{array}{c}\text { Year } t+1 \\
(2)\end{array}$ & $\begin{array}{c}\text { Year } t+2 \\
(3)\end{array}$ & $\begin{array}{c}\text { Year } t+3 \\
(4)\end{array}$ & $\begin{array}{c}\text { Year } t+4 \\
(5)\end{array}$ \\
\hline \multirow{3}{*}{ LATE } & 0.177 & 0.311 & 0.470 & 0.788 & 0.858 \\
& $(0.747)$ & $(0.753)$ & $(0.748)$ & $(0.766)$ & $(0.832)$ \\
\hline
\end{tabular}

Note: ${ }^{* *} \mathrm{p}<0.01$ and $* \mathrm{p}<0.05$. Table 7a presents estimates of the impact of falling in the manipulation region on log program revenue, while Table $7 \mathrm{~b}$ presents estimates of the effect of bunching on log program revenue. The counterfactual is estimated from linear regressions of log program revenue, estimated separately on both sides of the cut-off. The counterfactual uses only data from outside the manipulation region. Standard errors are calculated using the parametric bootstrap procedure described in the text. 


\section{Table 8a: Reduced Form: Impact of Falling in Manipulation Region on Sample Exit}

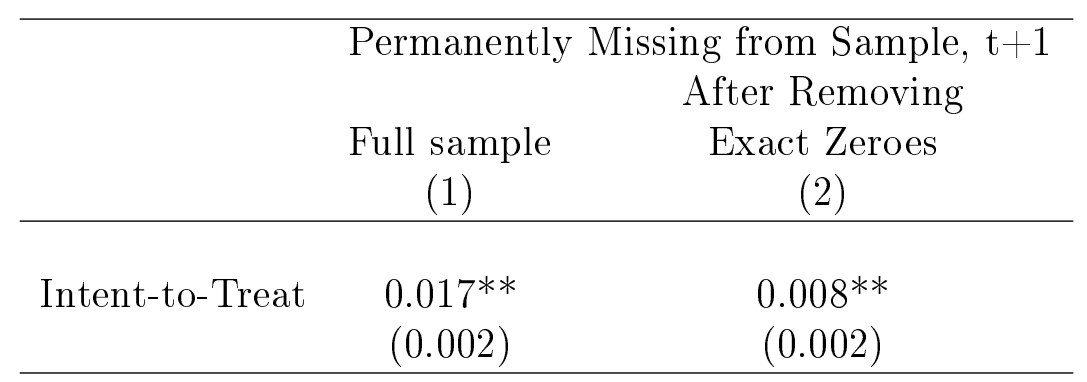

Table 8b: Impact of Bunching on Sample Exit (LATE)

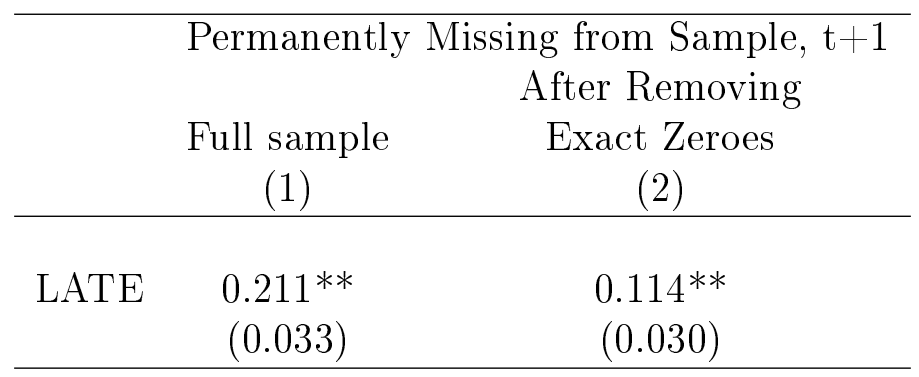

Note: ${ }^{* *} \mathrm{p}<0.01$ and ${ }^{*} \mathrm{p}<0.05$. Table 8 a presents estimates of the impact of falling in the manipulation region on permanent exit from the sample, while Table $8 \mathrm{~b}$ presents estimates of the effect of bunching on permanent exit. The counterfactual is estimated from linear regressions of charity exit, estimated separately on both sides of the cut-off. The counterfactual uses only data from outside the manipulation region. Standard errors are calculated using the parametric bootstrap procedure described in the text. 


\section{Appendix Figure 1: Density Distribution by Age}
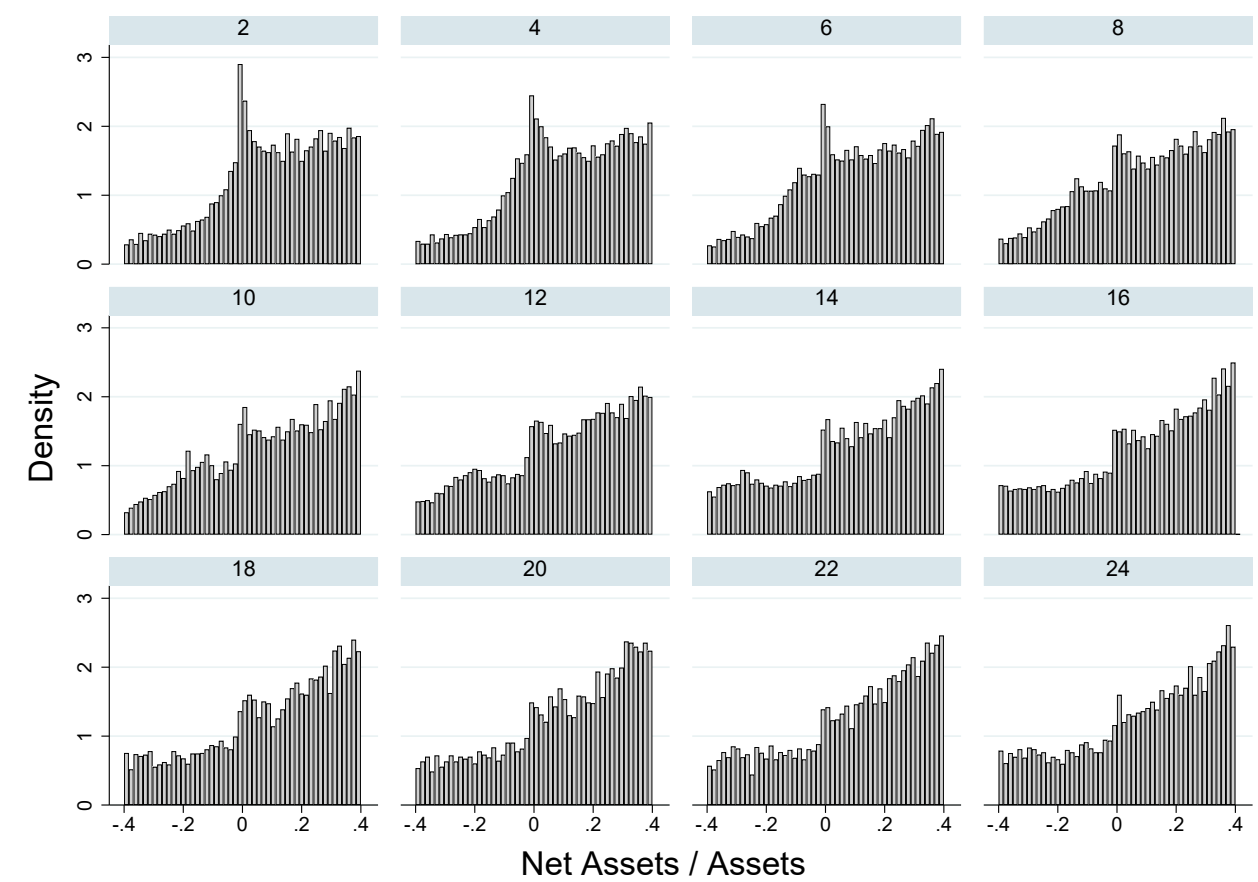

Note: This figure presents the density distribution by net assets for charities of different ages. The age of the charity is based on the year in which the IRS recognized the organization's tax exempt status, as reported on the Form 990. 


\section{Appendix Figure 2: Extensive Margin Responses}

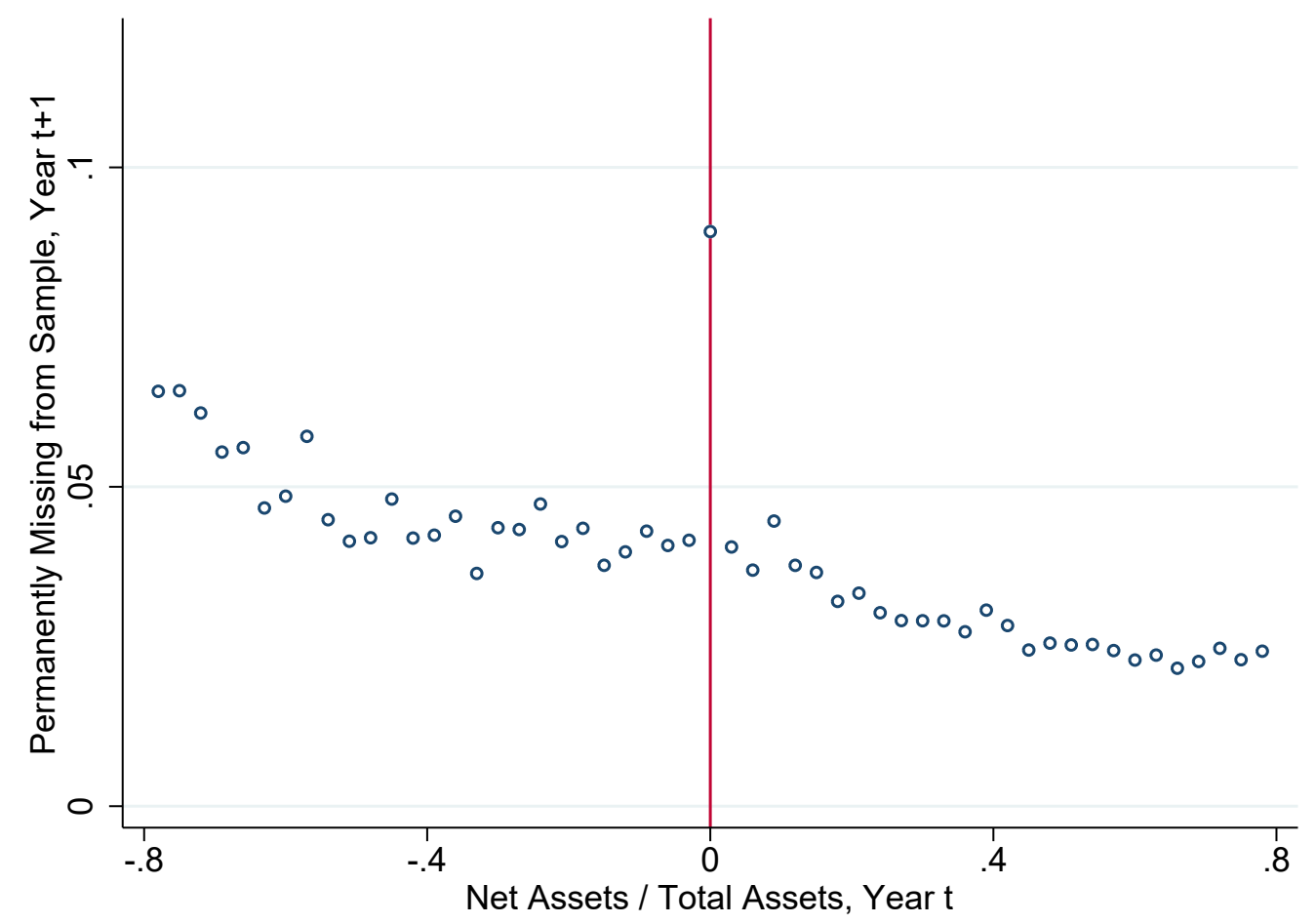

Note: This figure plots the running variable (net assets in year $t$ ) against a measure of sample attrition (whether the firm permanently exited the sample in year $t+1$ ). 


\section{Appendix Table 1: Sample Restrictions}

\begin{tabular}{|c|c|c|}
\hline Restriction & $\begin{array}{c}\text { Number of } \\
\text { Observations Lost }\end{array}$ & Sample Size \\
\hline Full Sample & & $3,485,306$ \\
\hline $\begin{array}{l}\text { Exclude charity-year observations with missing assets, } \\
\text { reported assets of zero or } 1 \text {, or charities with consecutive } \\
\text { years of exactly zero net assets. }\end{array}$ & $-320,178$ & $3,165,128$ \\
\hline $\begin{array}{l}\text { Exclude charities in operation for less than five years or } \\
\text { lacking data on year of IRS recognition. }\end{array}$ & $-491,616$ & $2,673,512$ \\
\hline $\begin{array}{l}\text { Exclude charities that report an average net income of } \\
\text { exactly zero or average contributions of exactly zero. }\end{array}$ & $-165,993$ & $2,507,519$ \\
\hline Exclude "supporting" public charities & $-325,826$ & $2,182,693$ \\
\hline
\end{tabular}

Note: The raw data consists of 3,485,306 observations and 578,282 charities and comes from the National Center of Charitable Statistics' (NCCS) 2005-2015 core files for public charities. The final sample consists of 2,182,693 observations and 331,568 charities. 


\section{Appendix Table 2: BIC for Different Polynomial Choices}

\begin{tabular}{lc}
\hline Polynomial Order & BIC \\
\hline First & -203.0166 \\
Second & -249.8154 \\
Third & -254.8452 \\
Fourth & -275.8825 \\
Fifth & -275.5269 \\
Sixth & -271.1752 \\
\hline
\end{tabular}

Note: The table reports the Bayesian Information Criteria for a series of regressions of nonprofit frequency on various polynomials of net assets. 


\section{Appendix Table 3: Sensitivity of Impact Estimates to Sample Restrictions}

1. Exclude charity year observations with missing assets, reported assets of zero or one, and charities with consecutive years of exactly zero net assets. This step cleans the data and ensures that the bunching we observe is not the spurious result of data entry errors.

\begin{tabular}{cccccc}
\hline & Year $t$ & Year $t+1$ & Year $t+2$ & Year $t+3$ & Year $t+4$ \\
$(1)$ & $(2)$ & $(3)$ & $(4)$ & $(5)$ \\
\hline \multirow{3}{*}{ Log Contributions } & 0.039 & $0.068^{*}$ & $0.072^{*}$ & 0.056 & -0.023 \\
& $(0.026)$ & $(0.027)$ & $(0.031)$ & $(0.033)$ & $(0.037)$ \\
\hline
\end{tabular}

2. Exclude charities in operation for less than five years or lacking data on year of IRS recognition. As new organizations are more likely to report near-zero net assets, we limit our sample to organizations in existence for at least five years to ensure that the bunching we observe is not caused by the entry of new charities.

\begin{tabular}{cccccc}
\hline & Year $t$ & Year $t+1$ & Year $t+2$ & Year $t+3$ & Year $t+4$ \\
& $(1)$ & $(2)$ & $(3)$ & $(4)$ & $(5)$ \\
\hline Log Contributions & 0.030 & $0.073^{*}$ & $0.076^{*}$ & 0.060 & -0.035 \\
& $(0.026)$ & $(0.028)$ & $(0.032)$ & $(0.034)$ & $(0.036)$ \\
\hline
\end{tabular}

3. Exclude charities with zero average income or zero average contributions. We remove charities that report zero average income so as to address the possibility that some nonprofits cluster at zero as a result of a deliberate strategy of spending down all of their resources every year, as opposed to bunching in response to the zero net assets threshold.

\begin{tabular}{cccccc}
\hline & Year $t$ & Year $t+1$ & Year $t+2$ & Year $t+3$ & Year $t+4$ \\
& $(1)$ & $(2)$ & $(3)$ & $(4)$ & $(5)$ \\
\hline Log Contributions & 0.034 & $0.076^{* *}$ & $0.079^{*}$ & 0.063 & -0.032 \\
& $(0.026)$ & $(0.028)$ & $(0.032)$ & $(0.034)$ & $(0.036)$ \\
\hline
\end{tabular}

4. Exclude "supporting" public charities. This restrictions ensures that the bunching we observe is not due to subsidiary organizations that transfer all of their fund balance at year's end to a parent organization. 


\begin{tabular}{cccccc}
\hline & Year $t$ & Year $t+1$ & Year $t+2$ & Year $t+3$ & Year $t+4$ \\
& $(1)$ & $(2)$ & $(3)$ & $(4)$ & $(5)$ \\
\hline Log Contributions & 0.025 & $0.070^{*}$ & $0.074^{*}$ & $0.073^{*}$ & -0.037 \\
& $(0.025)$ & $(0.027)$ & $(0.031)$ & $(0.035)$ & $(0.037)$ \\
\hline
\end{tabular}

Note: ${ }^{* *} \mathrm{p}<0.01$ and ${ }^{*} \mathrm{p}<0.05$. This table shows the sensitivity of our estimates in Table 5 to the sample restrictions detailed in Appendix Table 1. After each restriction, we re-estimate the impact of falling in the manipulation region on log contributions. The last table shows the results for the full sample, reproducing the results from Table 5a. The counterfactual is estimated from linear regressions of log contributions on net assets, estimated separately on both sides of the cut-off. The counterfactual uses only data from outside the manipulation region. Standard errors are calculated using the parametric bootstrap procedure described in the text. 


\section{Appendix Table 4: Characteristics of Bunchers}

\begin{tabular}{|c|c|c|c|}
\hline & $\begin{array}{c}\text { Estimated } \\
\text { from Above } \\
(1)\end{array}$ & $\begin{array}{l}\text { Estimated } \\
\text { from Below } \\
(2)\end{array}$ & $\begin{array}{c}\text { Difference } \\
(3)\end{array}$ \\
\hline \multicolumn{4}{|l|}{ Type of Charity } \\
\hline Arts, Culture, \& Humanities & 0.094 & 0.098 & $\begin{array}{l}-0.004 \\
(0.020)\end{array}$ \\
\hline Education & 0.183 & 0.337 & $\begin{array}{c}-0.154^{* *} \\
(0.061)\end{array}$ \\
\hline Health and Human Services & 0.316 & 0.275 & $\begin{array}{c}0.042 \\
(0.118)\end{array}$ \\
\hline Other & 0.407 & 0.291 & $\begin{array}{c}0.116 \\
(0.061)\end{array}$ \\
\hline \multicolumn{4}{|l|}{ Financial Characteristics } \\
\hline Log Assets, $t-1$ & 12.2 & 13.4 & $\begin{array}{c}-1.28^{* *} \\
(0.324)\end{array}$ \\
\hline Log Revenue, $t-1$ & 13.3 & 16.8 & $\begin{array}{c}-3.41^{* *} \\
(0.697)\end{array}$ \\
\hline Percent Revenue from Contributions, $t-1$ & 0.746 & 0.767 & $\begin{array}{l}-0.021 \\
(0.066)\end{array}$ \\
\hline Reported Program Revenue (Yes/No), $t-1$ & 0.259 & 0.641 & $\begin{array}{c}-0.382^{* *} \\
(0.084)\end{array}$ \\
\hline Total Compensation as Percent of Expenses, $t-1$ & 0.253 & 0.611 & $\begin{array}{c}-0.359^{* *} \\
(0.083)\end{array}$ \\
\hline
\end{tabular}

Note: ** $\mathrm{p}<0.01$ and $* \mathrm{p}<0.05$. This table presents characteristics of the bunching charities. Column 1 reproduces the first column of results from Table 3 in which we estimate the characteristics of bunching charities using data above the threshold. Column 2 estimates the characteristics of the bunching charities using data below the threshold. Column 3 presents the difference between the estimates. Standard errors are calculated using the parametric bootstrap procedure described in the text. 


\section{Appendix Table 5a: Reduced Form: Impact of Falling in Manipulation Region on Contribution Revenue with Imputation of Missing Outcomes}

\begin{tabular}{ccccc}
\hline & \multicolumn{4}{c}{ Log Contributions } \\
& $\begin{array}{c}\text { Year } t+1 \\
(1)\end{array}$ & $\begin{array}{c}\text { Year } t+2 \\
(2)\end{array}$ & $\begin{array}{c}\text { Year } t+3 \\
(3)\end{array}$ & $\begin{array}{c}\text { Year } t+4 \\
(4)\end{array}$ \\
\hline \multirow{3}{*}{ Intent-to-Treat } & $0.067^{*}$ & 0.048 & $0.060^{*}$ & -0.035 \\
& $(0.025)$ & $(0.029)$ & $(0.029)$ & $(0.031)$ \\
\hline
\end{tabular}

\section{Appendix Table 5b: Impact of Bunching on Contribution Revenue (LATE) with Imputation of Missing Outcomes}

\begin{tabular}{ccccc}
\hline \multicolumn{5}{c}{ Log Contributions } \\
& $\begin{array}{c}\text { Year } t+1 \\
(1)\end{array}$ & $\begin{array}{c}\text { Year } t+2 \\
(2)\end{array}$ & $\begin{array}{c}\text { Year } t+3 \\
(3)\end{array}$ & $\begin{array}{c}\text { Year } t+4 \\
(4)\end{array}$ \\
\hline \multirow{3}{*}{ LATE } & $0.832^{*}$ & 0.590 & $0.749 *$ & -0.440 \\
& $(0.311)$ & $(0.355)$ & $(0.359)$ & $(0.397)$ \\
\hline
\end{tabular}

Note: ${ }^{* *} \mathrm{p}<0.01$ and ${ }^{*} \mathrm{p}<0.05$. The tables reproduce the results from Table 5 except that it imputes missing outcomes for charities that exit the sample. The imputation approach assumes that organizations continue the growth trend that they were on prior to their exit. For example, if a firm saw a 5 percent decrease between year $t-1$ and year $t$ before exiting in year $t+1$, then we assume contributions continued to decrease at a 5 percent rate in future years. 